\title{
Magnetic Bearing Update
}

\author{
T. K. Fowler
}

May 25, 1995

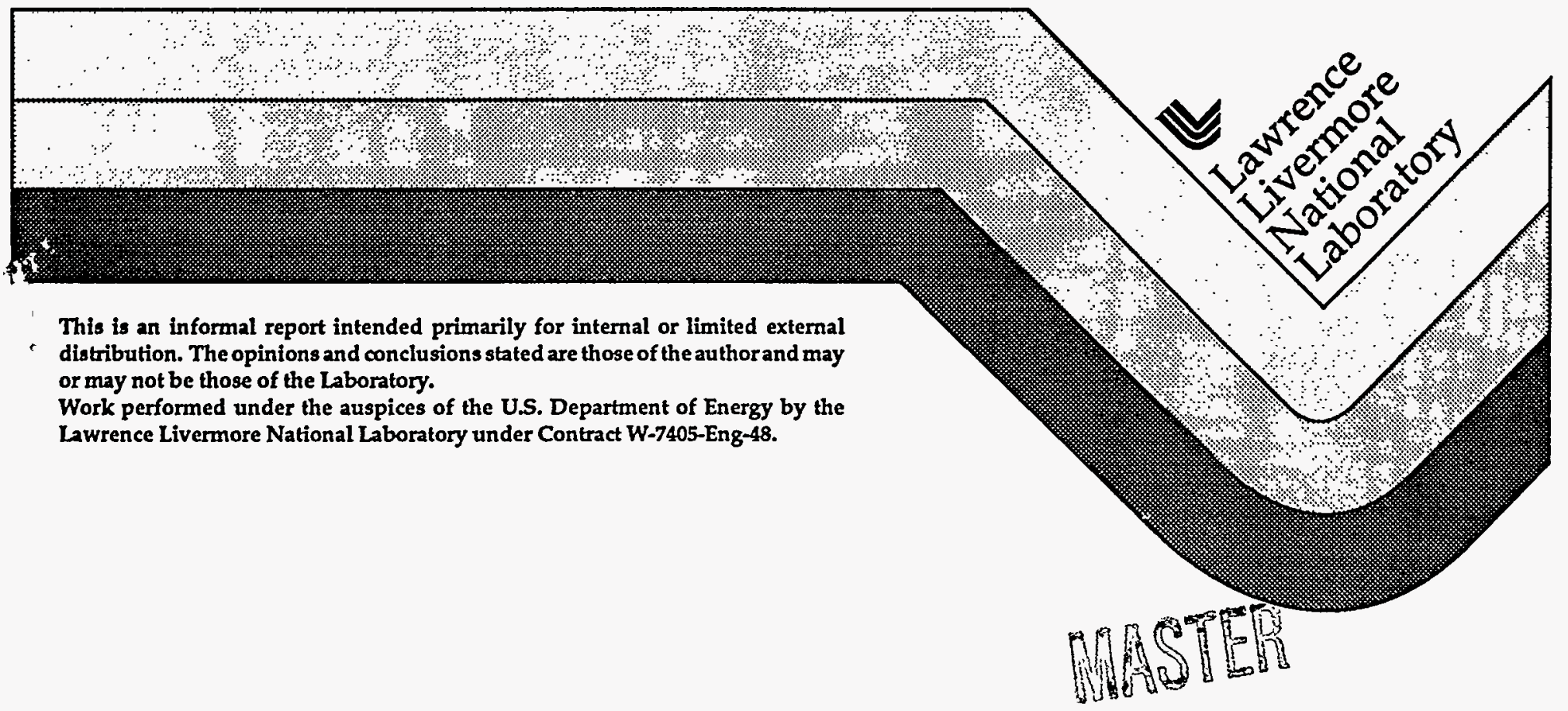

This is an informal report intended primarily for internal or limited external distribution. The opinions and conclusions stated are those of the author and may or may not be those of the Laboratory.

Work performed under the auspices of the U.S. Department of Energy by the Lawrence Livermore National Laboratory under Contract W-7405-Eng-48. 


\section{DISCLAIMER}

This document was prepared as an account of work sponsored by an agency of the United States Government. Neither the United States Government nor the University of California nor any of their employees, makes any warranty, express or implied, or assumes any legal liability or responsibility for the accuracy, completeness, or usefulness of any information, apparatus, product, or process disclosed, or represents that its use would not infringe privately owned rights. Reference herein to any specific commercial product, process, or service by trade name, trademark, manufacturer, or otherwise, does not necessarily constitute or imply its endorsement, recommendation, or favoring by the United States Government or the University of California. The views and opinions of authors expressed herein do not necessarily state or reflect those of the United States Government or the University of California, and shall not be used for advertising or product endorsement purposes.

This report has been reproduced directly from the best available copy.

Available to DOE and DOE contractors from the Office of Scientific and Technical Information P.O. Box 62, Oak Ridge, TN 37831

Prices available from (615) 576-8401, FTS 626-8401

Available to the public from the National Technical Information Service

U.S. Department of Commerce 5285 Port Royal Rd., Springfield, VA 22161 


\title{
Magnetic Bearing Update
}

\author{
T.K. Fowler
}

May 25, 1995

\begin{abstract}
Stabilization of whirl instability by floppy, viscous bearing mounts is discussed and required material properties are estimated for the new tilt-whirl mode in eddy-current stabilized magnetic bearings. A relatively low Young's modules $\mathrm{Y} \sim 10^{5}$ and high viscosity $\eta \sim 10^{7}$ are required (both in MKS units), suggesting the need for careful mounting design. New information on periodic bearings shows that, thus far, Earshaw's Theorem cannot be defeated by periodicity, despite the author's earlier claims.
\end{abstract}

Two topics identified in Ref. 1 have led to further work involving students in Mechanical Engineering at Berkeley. One result concerns the forces due to eddy-currents in eddycurrent stabilized bearings. ${ }^{2}$ Recently, these forces were shown to produce a tilting whirltype instability, ${ }^{3}$ later confirmed by Ryutov. ${ }^{4}$ The other subject is periodic bearings. ${ }^{5}$

\section{Review of Eddy-Current Stabilized Bearing}

In Ref. 3, it was shown that a whirl instability involving tilt motion may exist in eddycurrent stabilized magnetic bearings, and that this tilt-whirl would be more difficult to stabilize than the usual translational whirl instability encountered in many mechanical systems. Recently Ryutov has recovered these results in a more reliable way by reformulating the stability analysis for small angular perturbations in the proper way to linearize the equation. ${ }^{4}$ His equations for tilting motion, for a single rotor midway between identical axisymmetric bearings, are:

$$
\mathrm{I}_{1} \ddot{\theta}_{\mathrm{x}}+\mathrm{I}_{3} \dot{\theta}_{\mathrm{y}}=2 \mathrm{~K} \ell^{2} \theta_{\mathrm{x}}+2 \mathrm{~K} \mathrm{w} \ell^{2} \theta_{\mathrm{y}}-2 \mathrm{R}_{\mathrm{f}} \ell^{2} \dot{\theta}_{\mathrm{x}}
$$




$$
I_{1} \ddot{\theta}_{y}+I_{3} \dot{\theta}_{x}=-2 K \ell^{2} \theta_{y}+2 K_{w} \ell^{2} \theta_{x}-2 R_{f} \ell^{2} \dot{\theta}_{y}
$$

and for translation,

$$
\begin{aligned}
& M \ddot{x}=-2 K x+2 K_{w} y-2 R f \dot{x} \\
& M \ddot{y}=-2 K y-2 K_{w} x-2 R f \dot{y} .
\end{aligned}
$$

Here $M$ is the rotor mass; $I_{3}$ is the principal moment of inertia (about $z$, the rotor axis); $I_{1}$ is the other moment, about $\mathrm{x}, \mathrm{y} ; \mathrm{K}, \mathrm{K}_{\mathrm{w}}$ and $\mathrm{R}_{\mathrm{f}}$ are the bearing restoring force, whirl force and friction per bearing (hence multiplied by 2 ); $\Omega$ is the rotor speed (angular frequency); and $2 \ell$ is the length of the shaft between bearings. As is noted in Ref. 3, we are most interested in magnetic bearings stabilized by eddy-currents and mounted on "floppy" bearings. Then, effectively, the bearings and shaft are rigidly attached so that $K$ and $R_{f}$ are actually those of the mounting. There is, however, a residual bearing whirl force, shown in Ref. 3 to be:

$$
\mathrm{K}_{\mathrm{w}}=\left(\mathrm{K}_{\mathrm{w}}\right)_{\text {bearing }}\left(\frac{\mathrm{K}_{\text {mount }}}{\mathrm{K}_{\text {bearing }}}\right)^{2} \text {. }
$$

Since there is no slip relative to the mounting, the mounting friction itself does not produce a whirl torque.

The results of Ref. 3. are easily recovered by letting $\theta$ 's vary as exp pt, and (for different p's) $x, y$ also, translation and tilt being decoupled. ${ }^{3,4}$ Defining frequencies in units of $\left(2 \mathrm{~K} \ell^{2} / \mathrm{I}_{1}\right)^{1 / 2}$ for tilt and $(2 \mathrm{~K} / \mathrm{m})^{1 / 2}$ for translation, both tilt and translation eigenfrequency equations can be written as:

$$
\left(\omega^{2}+c \omega+1\right)^{2}=-(b-a \omega)^{2}
$$

where $c=R_{\mathbb{f}} / \mathrm{K}$ (a reciprocal frequency), $\mathrm{b}=\mathrm{K}_{\mathrm{w}} / \mathrm{K}$ and $\mathrm{a}=\left(\mathrm{I}_{3} \Omega / 2 \mathrm{~K} \ell^{2}\right)$ (a frequency) in the appropriate frequency units for the two cases. Solving Eq. (6) gives: 


$$
\omega=-\frac{c \pm i a}{2} \pm \sqrt{\left(\frac{c \pm i a}{2}\right)^{2}-1 \pm i b} .
$$

For translational whirl, $a=0$ and $b, c<<1$ so, expanding with -1 as the large term, we obtain

$$
\omega= \pm i+\frac{1}{2}(b-c)
$$

Then, recalling that $\omega \propto \mathrm{p}$ is the Laplace (not the Fourier) frequency, stability requires,

$$
c>b \text {. Translation }
$$

This is Eqs. (36) and (53) in Ref. 3.

For tilt-whirl, $a>1, b, c<1$ so, expanding with a as the large term gives a stable root $\omega=-i a-c$ for the negative sign, and for the positive sign

$$
\omega=i a^{-1}+a^{-1}\left(b-\frac{c}{a}\right) \text {. }
$$

Hence stability if

$$
c^{\prime}>b^{\prime} a^{\prime} \text {. Tilt }
$$

which is Eq. (52) of Ref. 3, and we have added primes to remind us that the frequency units in Eqs. (9) and (11) differ by $\left(\mathrm{I}_{1} / \mathrm{M} \ell^{2}\right)^{1 / 2}$, which is order unity. When the system is tilt-whirl unstable, the growth constant from Eq. (10) is $\mathrm{b}^{\prime} / \mathrm{a}^{\prime}$, which is Eq. (31) of Ref. 3. However, the implication in Ref. 3 that the mode is purely growing is incorrect since in Eq. (10) the real part is smaller by the factor $b<1$. 
Comparing Eqs. (9) and (11) shows that, in agreement with Refs. 3 and 4, the tilt-whirl is the more difficult to stabilize, by the large factor $\mathrm{a}^{\prime}$ (though its growth rate in the absence of frictional stabilization would be less than that for translational whirl by this same large factor). Note also that, the growth constant $b$ for translational whirl is actually the absolute value from $\left(b^{2}\right)^{1 / 2}$ when $a=0$, and the tilt-whirl growth rate $b^{\prime} / a^{\prime}$ depends on the relative sign for $\mathrm{K}_{\mathrm{w}}$ and $\Omega$. As Ryutov has pointed out, ${ }^{4}$ this means that in principle the tilt-whirl can be eliminated by design. The unstable case is the unusual one shown in Fig. 1, taken from Ref. 2, with the magnetic element inside and the eddy-current element outside. Inverting this arrangement should give tilt-whirl stabilization independent of mounting friction while the translational whirl can be stabilized either by the mounting friction or by clamping the bearing (oval shape) to create an asymmetry in the restoring force. ${ }^{1,3}$

\section{Frictional Stabilization of Tilt-Whirl}

The work of Ref. 2 provides numbers whereby the tilt-whirl frictional stabilization criterion, Eq. (11), can be evaluated for a specific case. This work, from the Ph.D. thesis of W. Lorimer at U.C. Berkeley, ${ }^{2}$ provides values for $\mathrm{K}_{\mathrm{w}}$ and $\mathrm{K}$ for the magnetic bearing itself. The commercial code utilized for the calculations could presumably be used to calculate these numbers for other bearing designs as well.

Restoring the units, Eq. (11) becomes:

$$
\Omega<\omega_{\mathrm{o}}\left(\mathrm{K}_{\mathrm{b}} / \mathrm{K}_{\mathrm{wb}}\right)\left(\mathrm{K}_{\mathrm{b}} / \mathrm{K}_{\mathrm{m}}\right) .
$$

The code calculates $\mathrm{K}_{\mathrm{b}} / \mathrm{K}_{\mathrm{wb}}$, while the other factor is a frequency relating rotor and mounting parameters:

$$
\omega_{0}=\frac{R_{m} \ell^{2}}{I_{3}} \simeq \frac{R_{m}}{M} .
$$

The factor $\mathrm{K}_{\mathrm{b}} / \mathrm{K}_{\mathrm{m}} \gg>1$ for a "floppy" bearing, and Lorimer finds $\mathrm{K}_{\mathrm{b}} / \mathrm{K}_{\mathrm{wb}} \simeq 3$ (see Fig. 2). Hence, the stability requirement would be 


$$
\Omega<3 \frac{\mathrm{K}_{\mathrm{b}}}{\mathrm{K}_{\mathrm{m}}} \omega_{\mathrm{o}}
$$

The coefficient in Eq. (14) could be increased another order of magnitude or more by an improved eddy-current stabilization design. Then

$$
\Omega<100 \omega_{\mathrm{o}},
$$

where the larger coefficient corresponds to the improved design.

From Eq. (13), we can see that $\omega_{0}$ is the effective frequency appearing in the viscous frictional force, $R_{m} \dot{x}$, for the mounting:

$$
R_{m}=\eta \frac{A}{d} \cong \eta t_{m}
$$

where $A$ is the area of surfaces moving relative to each other and $d$ is their separation distance, the ratio being roughly the thickness $t_{m}$ of the mounting material; and $\eta$ is the coefficient of viscosity of the material. Combining Eqs. (12) - (16) gives us the required viscosity for stabilization

$$
\eta>\left(\frac{K_{w b}}{K_{b}}\right)\left(\frac{K_{m}}{K_{b}}\right)\left(\frac{M \Omega}{t_{m}}\right) \cong 10^{7}(M K S)=10^{8} \text { poise, }
$$

valid for $\Omega=2 \cdot 10^{6}(200,000 \mathrm{RPM})$ and a typical rotor mass of $4 .-5 \mathrm{~kg}$ and the mounting thickness $\mathrm{t}_{\mathrm{m}}=.01 \mathrm{~m}$. The range of values corresponds to that in Eq. (15), the lower value of $\eta$ corresponding to the higher value of $\mathrm{K}_{b} / \mathrm{K}_{\mathrm{wb}}$ for the improved bearing design. 
To be "floppy" we also require $\mathrm{K}_{\mathrm{m}} \ll \mathrm{K}_{\mathrm{b}}=\frac{\alpha(\mathrm{Mg})}{\mathrm{dx}}$ or $\mathrm{K}_{\mathrm{m}} \sim \frac{\mathrm{Mg}}{\mathrm{dx}} \cong 10^{3}$ to $10^{4}$ for a displacement $\mathrm{dx} \ll 1 \mathrm{~cm}, \mathrm{M}=4 \mathrm{~kg}, \alpha=0.3$ to $3, \mathrm{~g}=10$ (gravity, MKS). The spring constant is related to the Young's modulus by

$$
K_{m}=Y_{m} \frac{A_{m}}{t_{m}}
$$

or, for typical dimensions, $\mathrm{Y}_{\mathrm{m}} \cong 10^{5}-10^{6}$ (MKS: newton $\left./ \mathrm{m}^{2}\right)$.

Thus we would like a mounting having effective bulk properties of a Young's modulus around $10^{5}$ and viscosity around $10^{7}$ in MKS units. Solid rubber has $Y=10^{6}$ and a highly viscous fluid like pitch has $\eta=10^{10}$, suggesting that a spongy synthetic, or a composite with springy wires and a viscous matrix, might be required.

To conclude this section, we note that it is not clear that the tilt-whirl instability has ever been observed. Attempting to do so would seem to be a high priority as a test of Ryutov's theory, and as a prudent investigation into future problems if the tilt-whirl theory is correct.

\section{Periodic Bearings}

We conclude this note with an acknowledgment that, despite implications to the contrary in Ref. 1, we have in fact not found any periodic bearing system that is stable without the aid of eddy-current damping. So far as we know now, at best periodic bearings would be neutral with no net restoring force, or unstable. The case in Ref. 1 that was claimed to be stable was in fact a case of neutral forces, as the drawing for this case clearly indicated despite the wrong statements in the text (see Fig. 4A of Ref. 1). As usual, the issue revolves around the ratio of lateral (to the shaft) and axial forces, a ratio $1: 2$ being the origin of Earshaw's theorem often cited as the proof that no stable bearing exists based on the frozen-in fields of permanent magnets above. In Ref. 1 these ratios were estimated very crudely. However, Thomas Chang, a U.C. Berkeley graduate student, has carried out accurate numerical calculations for various cases in Ref. 1, always finding the fixed 1:2 ratios for circular magnets and corresponding values for non-circular ones that lead to the 
negative conclusion reported above, in agreement with the actual drawings in Ref. 1 (but not the optimistic text, for which the present author takes full responsibility). One of the more interesting of Mr. Chang's results concerns an array of four circular magnets mounted "vertically" on the rotor (magnet face parallel to the axis), offset axially from a corresponding fixed set. The results are shown in Table 1, which gives effective spring constants obtained from the numerically calculated forces due to a displacement. The Ks are given in units relative to $\mathrm{K}_{\mathrm{y}}$, and $\mathrm{d}$ is the diameter of the array. The combination of forces for the array gives (similar to the drawings in Ref. 1):

$$
\begin{aligned}
& \mathrm{K}_{\text {lateral }}=2\left(\mathrm{~K}_{\mathrm{x}}-\mathrm{K}_{\mathrm{y}}\right) \\
& \mathrm{K}_{\text {axial }}=4 \mathrm{~K}_{\mathrm{z}}
\end{aligned}
$$

As can be seen from the table, within the accuracy of the calculation $\mathrm{K}_{\mathrm{axial}}=2 \mathrm{~K}_{\text {lateral }}$ for all cases.

Table 1.

$\begin{array}{lllll}\text { Z-offset } & \mathrm{Kx} & \mathrm{Ky} & \mathrm{Kz} & \mathrm{K}_{\text {axial }} / \mathrm{K}_{\text {lateral }} \\ 0.0 * \mathrm{~d} & 2.0 & 1.0 & 1.0 & 2.0 \\ 0.1 * \mathrm{~d} & 1.94 & 1.0 & 0.54 & 2.0 \\ 0.2 * & 1.77 & 1.0 & 0.76 & 2.0 \\ 0.3 * \mathrm{~d} & 1.54 & 1.0 & 0.53 & 2.0 \\ 0.4 * \mathrm{~d} & 1.27 & 1.0 & 0.27 & 2.0\end{array}$

\section{Acknowledgments}

I would like to thank Professor Dennis Lieu of the Mechanical Engineering Department at the University of California - Berkeley, and his students Wendy Lorimer and Thomas Chang, for valuable discussions and for the use of their results quoted here. 


\section{$\underline{\text { References }}$}

1. D. E. Baldwin, T. K. Fowler, and R. F. Post, "Status of Passive Magnetic Bearing Design," controlled distribution, Lawrence Livermore National Laboratory report number UCRL-ID-114231, July 21, 1993.

2. Wendy Lorimer, "Effect of Eddy Currents on the Performance of ElectroMechanical Devices," Ph.D. thesis, Department of Mechanical Engineering, University of California - Berkeley, May 1995.

3. T. K. Fowler, "Whirl Plus Tilt," Lawrence Livermore National Laboratory report number UCRL-ID 118981, October 12, 1994.

4. T. K. Fowler, R. F. Post, and D. D. Ryutov, "Linear Stability of Two Elastically Coupled Rotors (axismmetry) System," in preparation.

5. Thomas Chang, Department of Mechanical Engineering, University of California Berkeley, private communication. 


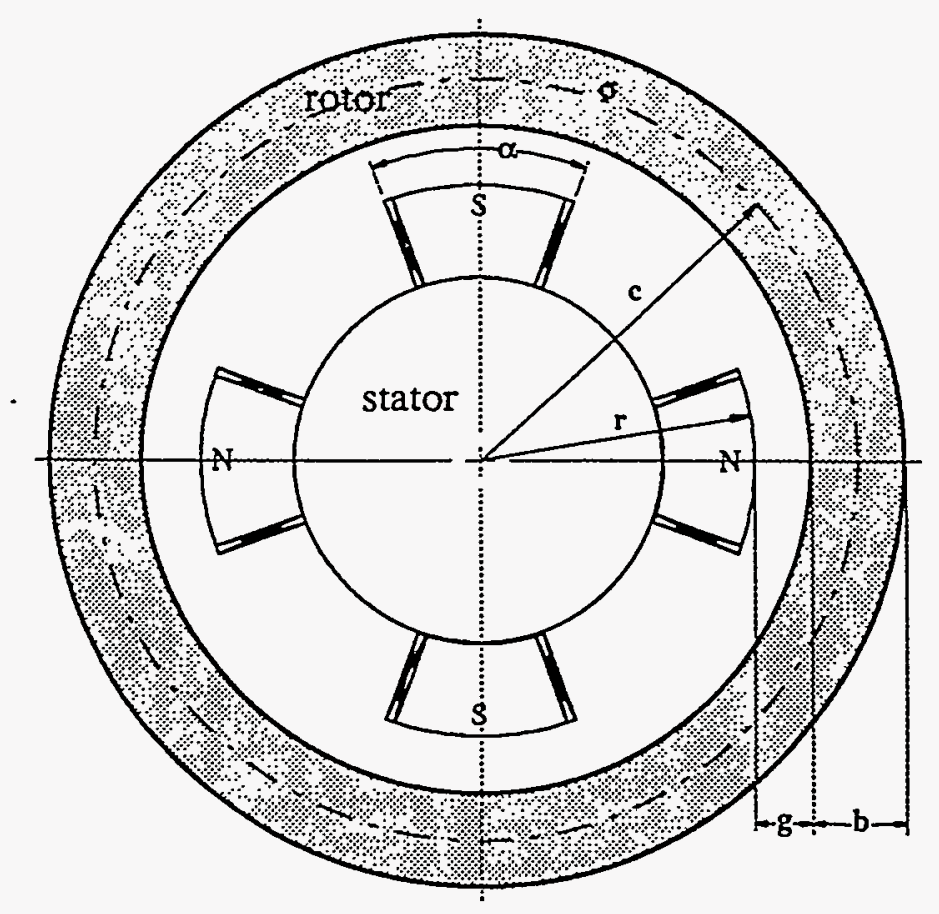

Figure 1. Radial flux passive eddy-current bearing

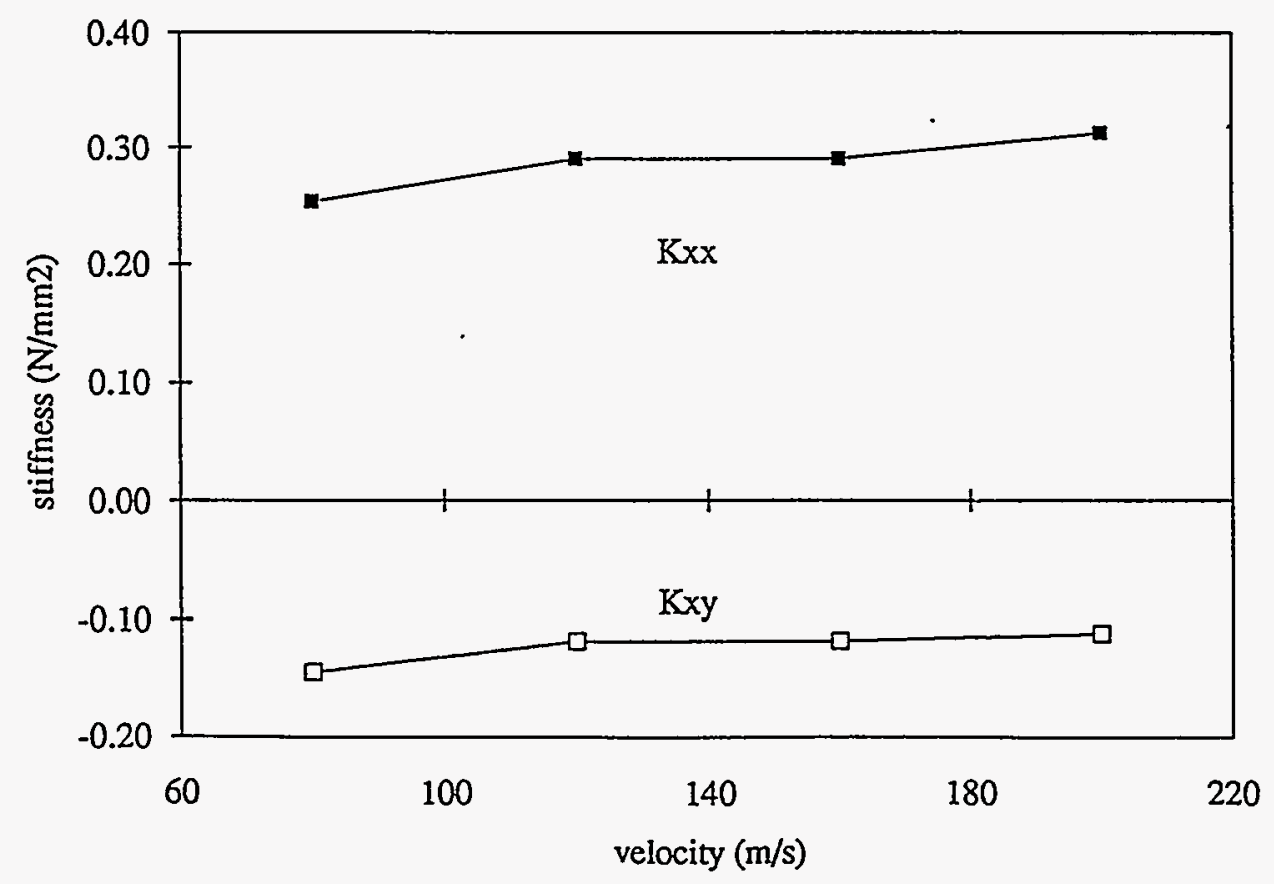

Figure 2. Effect of velocity on moderate displacement stiffness 
.

$a$ 

Technical Information Department • Lawrence Livermore National Laboratory University of California • Livermore, California 94551

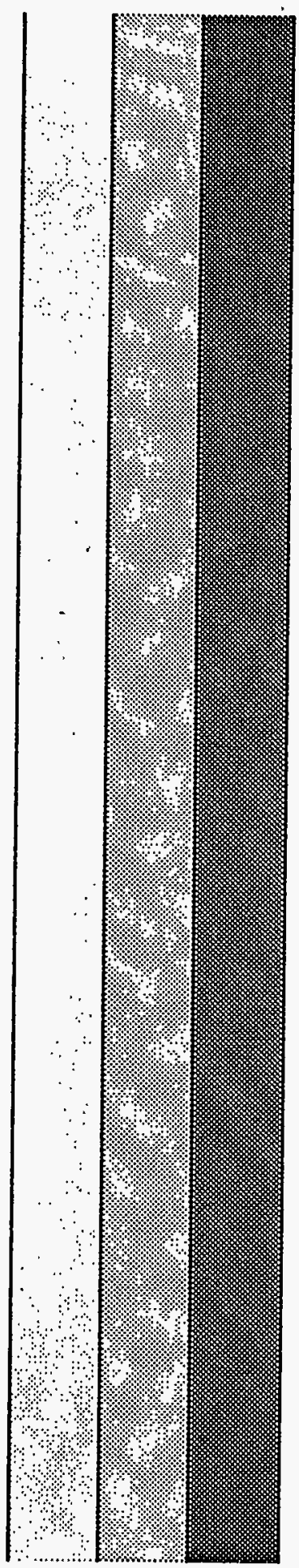

